\title{
CONSTRUÇÕES CORRELATAS ADITIVAS NO SÉCULO XVIII: UMA ANÁLISE SOB A PERSPECTIVA DA LÍNGUISTICA FUNCIONAL CENTRADA NO USO
}

Ivo da Costa do Rosário (UFF) Brenda da Silva Souza (UFF)

Resumo: Este artigo tem como objetivo apresentar uma análise qualiquantitativa das construções correlatas aditivas em uso no século XVIII, a partir de pressupostos teóricos da Linguística Funcional Centrada no Uso. Com base em um corpus de língua real, constituído de dados extraídos do site www.brasiliana.usp.br, foram detectadas 108 ocorrências, distribuídas em onze diferentes types de correlatores aditivos, marcados por alta diversidade morfossintática. Devido aos seus traços tanto formais quanto funcionais, defendemos que a correlação aditiva é uma estratégia distinta da coordenação aditiva.

Palavras-chave: Correlação; Adição; Linguística Funcional Centrada no Uso.

Abstract: This paper aims to present a quali-quantitative analysis of additive correlative constructions in use in the eighteenth century, based on the theoretical assumptions of Usage-Based Functional Linguistics. Based on a real language corpus with data extracted from the website www.brasiliana.usp.br, one hundred and eight occurrences, distributed in eleven different types of additive correlators, were detected, with high morphosyntactic diversity. Because of its formal and functional characteristics, we argue that additive correlation is a different strategy from the additive coordination.

Keywords: Correlation; Addition; Usage-Based Functional Linguistics.

\section{CONSIDERAÇÕES INICIAIS}

Neste trabalho, propomos apresentar algumas reflexões e análises realizadas com base nas construções correlatas aditivas 
a partir de dados coletados no espaço temporal do século XVIII. Partimos da hipótese de que a correlação aditiva distinguese da coordenação aditiva tanto no plano sintático quanto semântico-pragmático, conforme apontam Rosário (2009, 2012, 2013, 2015, 2017) e Gervásio (2016). Como exemplo da construção em foco, apresentamos o dado seguinte:

(01) O Canamo não sómente póde ter toda força, e solidez desejada, mas tambem por nossos trabalhos póde adquirir a doçura, e flexibilidade necessária a todos os usos, para que se destinar.[...] (p.52, L.7 $\left.{ }^{1}\right)$

Entendemos que a adição não está circunscrita aos processos de parataxe, sendo possível sua expressão por meio de outros processos morfossintáticos. A partir dessa premissa, defendemos que a correlação aditiva deve ser analisada como um fenômeno linguístico distinto da coordenação, fugindo das rígidas classificações advogadas pelos principais gramáticos de nosso país.

Desde já, assumimos a definição de correlação aditiva proposta por Rosário(2012, p.3): “Construção sintática prototipicamente composta por duas partes interdependentes e relacionadas entre si, encabeçadas por correlatores, de tal sorte que a enunciação de uma (prótase) prepara a enunciação de outra (apódose)".

1 Todos os dados desta pesquisa, extraídos do corpus www.brasiliana.usp.br, serão sucintamente identificado pelas letras p (página) e L (livro). Mais informações estão na seção de pressupostos teórico-metodológicos. 
Com base em Traugott e Dasher (2002, p. 9), para quem "diferenças na estrutura sintática refletem diferenças no significado construcional", defendemos que a coordenação aditiva, de fato, cumpre propósitos comunicativos distintos da correlação aditiva, foco deste estudo.

Contrariando a visão tradicional, que não considera a correlação como um processo de concatenação de orações distinto da coordenação e da subordinação, apoiamo-nos na Linguística Funcional Centrada no Uso (LFCU) para defender que a correlação merece ser analisada e mais bem descrita em termos sintáticos, semânticos, pragmáticos e discursivos como um terceiro processo de ligação entre cláusulas.

Com o intuito de perseguir esses objetivos, este artigo está dividido em cinco partes. Após estas considerações iniciais, passamos a uma breve revisão da literatura, com a finalidade de abordar como a correlação aditiva tem sido tratada por alguns gramáticos e linguistas em geral. Em seguida, apresentamos os pressupostos teórico-metodológicos que embasam este trabalho. Na sequência, chegamos à análise dos dados. Por fim, traçamos algumas considerações finais e listamos as referências utilizadas neste estudo.

\section{REVISÃO DA LITERATURA}

Sendo este um trabalho que se volta para a investigação das construções correlatas aditivas, consideramos pertinente 
partir da revisão de algumas obras que abordam a correlação e a coordenação. Primeiramente, consideraremos as visões dos principais autores de gramáticas e, posteriormente, observaremos também as diferentes interpretações de outros autores mais alinhados ao nosso ponto de vista teórico.

Em primeiro lugar, é necessário dizer que, de modo geral, a correlação, principalmente a aditiva, é vista pela Gramática Tradicional (GT) como um fenômeno sintático que integra o que se denomina comumente coordenação, isto é, a maioria dos autores não vê a correlação aditiva em um estatuto de integração diferente, mas como parte das construções coordenadas. Outros sequer a mencionam em seus escritos ou, quando dissertam sobre o assunto, o fazem de uma maneira muito superficial. Por essas razões, fomos motivados a pesquisar essa temática de forma mais aprofundada, procurando entender melhor esse objeto ainda pouco estudado: a correlação aditiva.

Luft (2000) defende que só existem dois processos de estruturação sintática: a coordenação e a subordinação, em um par opositivo. $\mathrm{O}$ autor até admite que alguns gramáticos consideram a existência de outros dois processos (a correlação e a justaposição), mas assevera que essa não é sua opinião, já que não vê razões para classificá-los como 
processos distintos de composição do período. Para ele, são apenas "tipos especiais de conexão que se estabelecem dentro da coordenação e da subordinação" (LUFT, 2000, p.47), e encerra a questão, demonstrando que a correlação aditiva, na visão dele, seria uma coordenação enfática, isto é, uma espécie de subtipo de oração coordenada aditiva.

Kury (2003, p.66) e Cunha e Cintra (2001, p.593) compartilham a mesma visão dicotômica de Luft (2000). O primeiro classifica as orações do tipo não só $X$, mas também $Y$ como pertencentes ao rol das coordenadas aditivas, sendo um subtipo que ele denomina "aditiva com correlação", já que cada oração possui um termo da locução conjuntiva. Já os dois últimos autores importam-se mais com o esclarecimento da bipartição coordenação x subordinação e, quando explicam aquela, classificam-na pelo critério da independência semântica, de modo que, para eles, o período composto por coordenação é aquele em que as orações são autônomas, cada uma com sentido próprio, completo. Não há espaço, portanto, nos escritos de Cunha e Cintra (2001), para o tema da correlação.

Diferentemente de Cunha e Cintra (2001), que optam pelo viés semântico, Bechara (2003) define a coordenação pelo critério da independência sintática. Para o autor, o que caracteriza um período composto por coordenação 
é o fato de as orações que o integram possuírem todos os "termos sintáticos previstos na relação predicativa" (p.49), não configurando, portanto, uma relação de dependência entre os elementos. Nessa obra, o fenômeno da correlação também não recebe grande atenção.

Em outro momento, na obra Moderna Gramática Portuguesa (BECHARA, 2009, p.330), o gramático alinha-se ao pensamento de Luft (2000) e disserta sobre as chamadas "conjunções coordenativas enfatizadas", citando expressões como "não só... mas também; não só... mas ainda" etc. Segundo seu ponto de vista, esses segmentos representam apenas recursos de ênfase que se dão por meio do arranjo sintático da coordenação.

Rocha Lima (1999, p.261) também segue esse mesmo raciocínio quando afirma que utilizamos uma "fórmula correlativa" do tipo não só... mas também, não só... mas ainda, não só... senão também etc. com o objetivo de "dar mais vigor à coordenação", assumindo o processo da correlação não como distinto, mas como um tipo de coordenação com um fim específico.

Ribeiro (2004), por sua vez, defende que a correlação e a justaposição não estão no mesmo plano da coordenação e da subordinação. Ele afirma que as primeiras dizem respeito ao modo de ligação das orações, e as últimas sobre 
o seu valor sintático de independência ou dependência no contexto em que se inserem. Sob a ótica desse autor, a correlação e a justaposição continuam não sendo processos de concatenação à parte, mas apenas modos diferentes de arranjo dentro dos chamados "processos universais" - a coordenação e a subordinação (RIBEIRO, 2004, p.306).

Já Henriques (2003, p.95), em uma análise bastante lacônica, não se aprofunda no tema da correlação. Restringese a alocar as correlatas aditivas dentro do bloco das orações coordenadas sindéticas aditivas, como fazem os gramáticos em geral.

Em uma visão diferente da dos autores supracitados, Melo (2001, p.152-154) considera a correlação como um terceiro processo sintático, além da coordenação e da subordinação. Para o autor, a correlação é caracterizada como um processo complexo em que há interdependência entre as orações, e ainda destaca subtipos: correlação consecutiva, comparativa, equiparativa e alternativa.

Mateus et al (2003) abordam a temática, sobretudo no que diz respeito às conjunções correlativas, contudo não chegam a descrever a correlação como processo sintático de concatenação de orações distinto da coordenação.

Ao abordar as conjunções e as locuções conjuncionais, as autoras mencionam algumas conjunções correlativas, que, 
segundo elas, têm forma de uma expressão descontínua, e citam como exemplo as locuções não só... como, não só...mas também, tanto...como, ou...ou, ora...ora, nem...nem, quer... quer. As linguistas denominam coordenação binária uma "estrutura de coordenação que apresenta dois membros coordenados", e exemplificam esse tipo de coordenação, citando as locuções conjuncionais correlativas não só... como (também), não só...mas também (MATEUS et al, 2003, p.563-564). Percebe-se, portanto, que elas até descrevem o fenômeno da correlação de forma relativamente mais ampla do que a maioria dos autores já mencionados, mas ainda assim mantêm a correlação como um subtipo da coordenação.

Destacamos, ainda, o pensamento de Raposo et al. (2013) acerca do assunto. Os autores, quando tratam dos tipos de conjunções coordenativas e da estrutura interna da coordenação, dissertam sobre a chamada "coordenação correlativa", em contraste com o que denominam “coordenação simples". Para eles, a coordenação correlativa é formada por um grupo coeso semanticamente, ainda que os termos estejam separados, funcionando como uma espécie de tipo especial de coordenação, o que não foge muito das tradicionais visões sobre esse assunto. 
Castilho (2010), assim como Melo (2001), está mais alinhado ao nosso ponto de vista. O estudioso aborda a temática da correlação de uma maneira bastante diferenciada dos principais gramáticos brasileiros. Ele utiliza o termo "interdependência" ao se referir à relação entre as sequências correlatas, diferenciando-as das coordenadas (independentes) e das subordinadas (dependentes):

Se raciocinarmos em termo de teoria dos conjuntos, diremos que as sentenças independentes constituem conjuntos autônomos, as dependentes são conjuntos inseridos em outro conjunto, hierarquicamente superior, e as interdependentes são conjuntos que se interpenetram [...]. (CASTILHO, 2010, p.340)

Castilho (2010) defende ainda que as construções correlatas já estão bastante gramaticalizadas e são recorrentes, bem como sustenta a possibilidade da ocorrência de correlação também entre os sintagmas e até mesmo entre os constituintes dos sintagmas, o que torna suas contribuições não só muito importantes para novos estudos sobre esse tema, mas uma leitura essencial a ser contrastada com outras de cunho conservador.

Por fim, destacamos a visão do professor José Oiticica (1952), considerado precursor de um estudo mais atento das 
construções correlatas, especialmente em sua obra Teoria da Correlação, publicada na metade do século passado. O autor assume a existência de quatro diferentes estruturas para o período composto: coordenação, subordinação, correlação e justaposição (p.15).

Oiticica (1952, p.17), ao definir o processo da coordenação como "composição do período com orações autônomas (de declaratividade total), separáveis, ligadas por conjunção explícita ou não", deixa claro que não abarca, nesse grupo, a correlação, que, para ele, configura-se como um fenômeno bastante distinto, com peculiaridades próprias e características definidas. Ao mencionar a correlação, o autor cita como exemplo o período "Não somente Maria socorreu a pobre família, mas também adotou as duas órfãs" e explica:

Quando inicio a primeira oração por não somente (denotativo restritivo de negação), sou forçado a iniciar a segunda pela expressão mas também (ou outra equivalente: mas ainda, como ainda, como também, senão que, mas etc.), denotativa de inclusão. Os pensamentos estão conexos, neste caso, por dois termos que sempre, além disso, devem estar claros, embora possa aparecer o segundo encurtado (braquilogia) num simples mas, como. (OITICICA, 1952, p.21)

O autor destaca também a possibilidade de ocorrência da correlação dentro da cláusula, isto é, no nível suboracional, 
quando podem correlacionar-se, por exemplo, sujeitos, objetos diretos, adjuntos adverbiais etc. Logo, não se trata de um procedimento sintático restrito ao campo da conexão de orações.

Portanto, está claro que a visão de Oiticica (1952), nesse ponto, está alinhada à de Castilho (2010) e, em alguma medida, à de Melo (2001) e à de Rosário (2009, 2012, 2013, 2015, 2017). Essas constituem as principais referências desta pesquisa para o tratamento das construções correlatas aditivas. Com base nessa revisão, façamos uma breve exposição dos pressupostos teórico-metodológicos que balizam este estudo.

\section{PRESSUPOSTOS TEÓRICO-METODOLÓGICOS}

Este estudo apoia-se na corrente teórica denominada Linguística Funcional Centrada no Uso (LFCU), que reúne postulados da Linguística Funcional Clássica de vertente norte-americana e da Linguística Cognitiva, especialmente no modelo da Gramática de Construções. Na LFCU, o uso linguístico assume grande importância, sendo relacionado a propriedades icônicas e tendo suas estratégias interacionais destacadas como motivadoras da gramática (ROSÁRIO; OLIVEIRA, 2016, p.236).

Defende-se, nessa perspectiva, uma abordagem holística dos usos linguísticos, considerando que as construções não 
produzem sentido de forma isolada e, por isso, é necessário considerar as relações contextuais. Destacamos aqui, portanto, a importância da consideração dos elementos que figuram junto aos pares correlatos, colaborando para a construção do sentido do enunciado.

Outro ponto fundamental para essa concepção teórica é o conceito de construção gramatical, que Goldberg (1995) define como o pareamento entre forma e sentido, um "esquema simbólico a partir do qual são instanciados todos os componentes da gramática." (ROSÁRIO; OLIVEIRA, 2016, p.239). Esse modelo que denominamos abordagem construcional da gramática é, pois, essencialmente, uma teoria do uso. Nessa abordagem, a língua é concebida como uma rede de pares convencionalizados entre forma e significado, conforme asseveram Traugott e Trousdale (2013, p.1). A gramática, enfim, é vista como uma estrutura maleável, "que está num contínuo refazer-se" (CUNHA; COSTA; CEZARIO, 2015, p.42). Segundo essa concepção:

há uma simbiose entre gramática e discurso: o discurso e a gramática interagem e se influenciam mutuamente. A gramática é compreendida como uma estrutura em constante mutação/ adaptação, em consequência das vicissitudes do discurso. Logo, a análise de fenômenos linguísticos deve estar 
baseada no uso da língua em situação concreta de comunicação. (CUNHA; BISPO; SILVA, 2013, p.14).

Nessa perspectiva, não cabe, portanto, o estudo de frases artificiais ou isoladas de seu contexto ${ }^{2}$. Por isso, em nossa análise, consideramos fragmentos retirados de textos reais que circularam na sincronia em análise, reproduzidos em uma extensão considerável, a fim de permitir a inferência de informações contextuais, elementos relacionados etc.

Na metodologia adotada neste trabalho, o foco de análise é preferencialmente qualitativo, mas com suporte quantitativo, por meio da consideração de aspectos de frequência token ${ }^{3}$ e type ${ }^{4}$. Levamos em consideração tanto fatores de natureza intralinguística como fatores extralinguísticos. Afinal, um dos pressupostos da LFCU é a ideia de que "a estrutura da língua é motivada por fatores cognitivos, sociocomunicativos e linguísticos" (CUNHA; BISPO; SILVA, 2013, p.22).

No que diz respeito ao corpus de pesquisa, ressaltamos que é composto por textos de modalidade escrita em português europeu e brasileiro no período do século

2 A noção de contexto, no âmbito da LFCU, ainda é bastante polêmica e instável. Neste trabalho, definimo-lo como a inter-relação entre dimensões da forma e do sentido, com especial destaque para o ambiente textual-discursivo em que um determinado fenômeno linguístico se insere.

3 A frequência token, segundo Bybee (2007, p.338), refere-se ao número de vezes que um determinado dado aparece em um corpus.

4 De acordo com Bybee (2007, p.338), a frequência type diz respeito à frequência de aparecimento de um determinado padrão construcional. 
XVIII, obtidos no site brasiliana.usp.br. Os dados reunidos foram cuidadosamente analisados de acordo com seu type correspondente, como demonstra a Tabela 1 a seguir, que sintetiza os resultados gerais do estudo:

\begin{tabular}{|c|c|c|}
\hline PARES CORRELATIVOS (TYPES) & $\begin{array}{c}\text { NÚMERO DE } \\
\text { OCORRÊNCIAS }\end{array}$ & $\begin{array}{c}\text { PORCENTAGEM DE } \\
\text { OCORRÊNCIA }\end{array}$ \\
\hline Não só... mas também & 24 & $22,20 \%$ \\
\hline X... como também & 22 & $20,37 \%$ \\
\hline Não só... mas & 18 & $16,60 \%$ \\
\hline Não somente... mas também & 16 & $14,81 \%$ \\
\hline Não somente... mas & 11 & $10,18 \%$ \\
\hline Não só... mas ainda & 09 & $8,30 \%$ \\
\hline Não só... como também & 03 & $2,77 \%$ \\
\hline Não somente... porém & 02 & $1,85 \%$ \\
\hline Não só... mas até & 01 & $0,92 \%$ \\
\hline Não só... senão ainda & 01 & $0,92 \%$ \\
\hline Não somente... como & 01 & $0,92 \%$ \\
\hline Total & 108 & $\mathbf{1 0 0} \%$ \\
\hline
\end{tabular}

Tabela 1- Frequência de ocorrência token e type

Como explicitado na Tabela 1, obtivemos uma frequência type de 11 diferentes padrões, em um total de 108 dados recolhidos de 20 obras analisadas. Os dados coletados foram analisados de acordo com o padrão construcional a que estão ligados, de maneira que a análise da sequência englobasse aspectos contextuais e discursivos. Ademais, foi levada em consideração a distinção entre ocorrências suboracionais, oracionais ou supraoracionais, como sintetizamos no Gráfico 1 a seguir: 


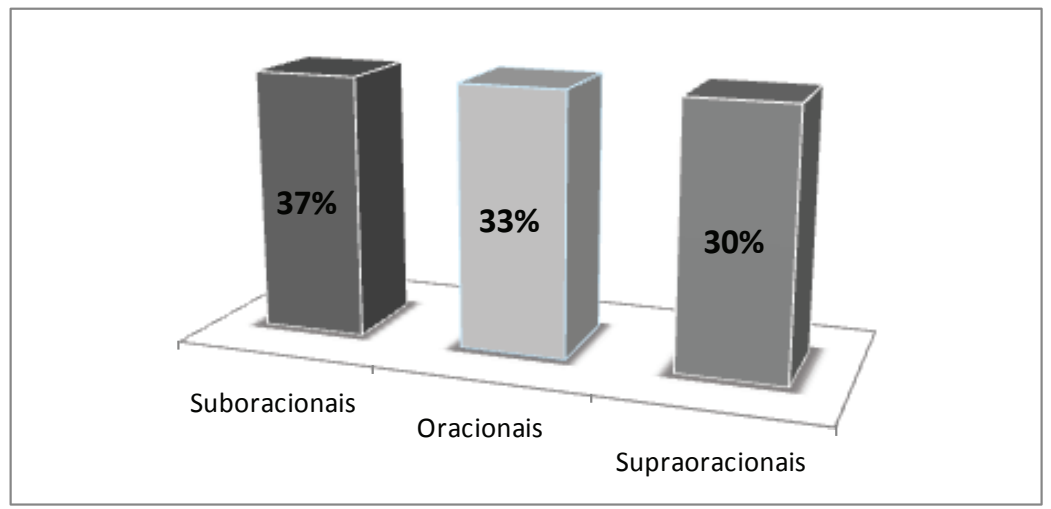

Gráfico 1 - Demonstrativo da porcentagem de ocorrências de construções correlatas aditivas suboracionais, oracionais e supraoracionais.

No que diz respeito à descrição dos dados encontrados, ratificamos que procuramos examinar não somente os aspectos formais das construções, tais como os fatores morfológicos e sintáticos de sua composição, mas também conferimos grande importância à já abordada questão da frequência de uso. Na abordagem construcional da gramática, a questão da produtividade, aqui diretamente relacionada à questão da frequência, nos termos de Bybee (2003; 2007), tem bastante importância, pois se entende que esse fator é responsável pela rotinização da construção nos diversos usos linguísticos.

Com base nessas asserções, passemos, então, à análise propriamente dita de alguns dados encontrados nos diferentes types. 


\section{ANÁLISE DE DADOS}

Nesta seção, apresentamos a análise de alguns types, por ordem de frequência. Por uma questão de limitação de espaço, não é possível apresentar aqui todos os types encontrados, com suas respectivas análises correspondentes. Assim, optamos por apresentar mais detalhadamente os quatro primeiros e os quatro últimos types indicados na Tabela 1, acompanhados de dados ilustrativos, extraídos do corpus:

O type não só... mas também é o mais recorrente em nossos dados coletados do século XVIII. Em termos de frequência token, a porcentagem de aparecimento desse padrão é de 24 ocorrências, ou seja, mais de $22 \%$ do total de nosso corpus.

(02) Para vindicarmos o innocente caffe deftas calumnias, devemos entre o ufo, e abufo delle fazer differença devemos tambem diftinguir os temperamentos, as idades, em que convém, daquelles, em que he nocivo: nos temperamentos biliofos, feccos, adultos principalmente na idade juvenil, he prejudicial naõ fó o abufo, mas tambem o ufo: excepto em alguma occafiaõ, que poderá fer remedio [...]. (p.14, L.5)

O exemplo (02) é bastante prototípico, no sentido de muito frequente. Nele, há uma sequência correlata aditiva suboracional - um tipo de ocorrência muito comum nos dados encontrados no século XVIII. Correlacionam-se, nesse 
caso, dois sintagmas nominais: "o abuso" e o "o uso", por meio do par correlato não só... mas também.

Ao analisarmos a estrutura da sequência em (02), baseados em uma concepção tradicional de língua e de gramática, como defendem alguns autores como Rocha Lima (1999), Luft (2000) e Kury (2003), facilmente concluiríamos que se trata de um caso de coordenação aditiva entre sintagmas não verbais, no qual o par correlato apenas traz um efeito de ênfase, como defende Bechara (2009, p.330). Para tais autores, essas expressões correlatas (não só... mas também; não só... mas ainda etc) são apenas recursos enfáticos que se dão por meio do arranjo sintático da coordenação.

De acordo com essa visão, os elementos que iniciam a prótase (não só) poderiam então ser facilmente omitidos, e os iniciadores da apódose (como também) poderiam ser substituídos pela conjunção coordenativa aditiva mais prototípica $e$, resultando em um enunciado semelhante ao ilustrado em $\left(02^{\prime}\right)$ :

(02') Para vindicarmos o innocente caffe deftas calumnias, devemos entre o ufo, e abufo delle fazer differença devemos tambem diftinguir os temperamentos, as idades, em que convém, daquelles, em que he nocivo: nos temperamentos biliofos, feccos, adultos principalmente na idade juvenil, he prejudicial (?) o abufo, e o ufo: excepto em alguma occafiaõ, que poderá fer remedio [...]. (adaptação nossa) 
Como afirmamos anteriormente, os usos exemplificados em (02) e em (02') seriam considerados por muitos autores tradicionais como idênticos do ponto de vista sintático, pois ambos seriam chamados de estruturas coordenadas aditivas. Igualmente seriam idênticos do ponto de vista semântico, pois há o efeito da adição entre os sintagmas nos dois casos, com a única diferença de que em (02) haveria mais ênfase.

Entretanto, consideramos que o efeito de sentido veiculado por não só... mas também é bastante diferente do enunciado adaptado em $\left(02^{\prime}\right)$. Apoiados no princípio da não sinonímia da forma gramatical, apresentado por Goldberg (1995, p.67), entendemos que diferenças na configuração sintática das construções implicam distinções semântico-pragmáticas. Nesse sentido, a seleção de determinados elementos em um ato comunicativo não é aleatória, mas motivada por intenções discursivas. Assim, a escolha pelo uso do par correlato não só... mas também ou da conjunção básica e não é algo imotivado, e por isso defendemos que o significado que emerge da utilização das duas construções é distinto.

No primeiro caso, percebe-se que os elementos que compõem a prótase e a apódose em (02) não estão no mesmo grau de igualdade como acontece na estrutura coordenada ilustrada em (02'). Em (02), há a ideia de um crescendum argumentativo, no qual o enunciado encabeçado por não 
só traz uma informação já conhecida, mais esperada, o que é demonstrado pelos próprios componentes associados. O elemento restritivo só é acrescido ao elemento de negação não, preparando o leitor para a informação seguinte, a qual será introduzida pelo mas que, nesse caso, traz uma ideia de acréscimo, associada ao típico inclusivo também, compondo o mas também, que traz a informação nova, não esperada no contexto.

Por esse motivo, do ponto de vista semântico, podemos postular que o significado expresso pela construção correlata aditiva em (02) não é o mesmo que o observado em (02'), em que dois sintagmas nominais são postos lado a lado, em uma estrutura básica de adição.

Caso parecido com o que ocorre na primeira construção exemplificada é a sequência ilustrada a seguir, em (03), que é uma construção correlata aditiva também bastante frequente. São correlacionados dois sintagmas preposicionados ("de alicerce [para a planta se ter em pé]" e "de dispenseira"), por meio do par correlato não só... mas também. Vejamos:

(03) Hecerto, que as unicas substancias, que entrão no nutrimento da planta, são a agoa, e o ar; (1) mas he necessário quem distribua estes nutrimentos aos vegetaes; para esse fim destinou a Natureza a mesma terra, pelo que ella serve, não só de alicerce para a planta se ter em pé, mas tambem de dispenseira, permitta-se-me esta expressão [...]. (p.19-20, L.8) 
Já na sequência adaptada a seguir, verificamos que há outro efeito de sentido quando retiramos os elementos que compõem o par correlato e que encabeçam a prótase e a apódose. Vejamos como ficaria o mesmo dado com o uso da conjunção coordenativa aditiva $e$ :

(03') Hecerto, que as unicas substancias, que entrão no nutrimento da planta, são a agoa, e o ar; (1) mas he necessário quem distribua estes nutrimentos aos vegetaes; para esse fim destinou a Natureza a mesma terra, pelo que ella serve (?) de alicerce para a planta se ter em pé, e de dispenseira, permitta-se-me esta expressão [...]. (adaptação nossa)

À semelhança da comparação feita entre (02) e $\left(02^{\prime}\right)$, verificamos que entre as sequências (03) e (03'), a diferença na forma gramatical entre os dois casos provocou a emergência de um novo significado. Em (02), a primeira parte do par correlato que encabeça a prótase é constituída pelo conjunto não só, o que provoca uma desrestrição sobre o sintagma "o abuso", que já seria esperado como um prejuízo com relação à ingestão de café. Na segunda parte da construção correlata, acrescenta-se o mas - elemento de contraexpectativa - associado ao focalizador também, evidenciando que até mesmo o "uso" - uma informação inesperada sobre o consumo de café - é nocivo a determinadas pessoas em algumas condições. Em contrapartida, esse jogo de informações não ocorre na sequência em (02'), que apenas 
expõe lado a lado duas informações, adicionando-as, sem essas nuances entre dado e novo que ocorre na correlação.

Em (03), retira-se o foco da informação já conhecida (de que a terra serve de "alicerce" para a planta), para ressaltar o fato de que ela também é uma espécie de "dispenseira". Por outro lado, em (03'), à maneira de (02'), não há essa relação de focalização entre os componentes da sentença, mas apenas a adição de duas informações de mesmo nível, sem esse jogo entre informação dada e informação nova.

Para melhor entendermos essa relação entre dado e novo, é importante pensar na já citada noção de crescendum argumentativo, nos termos de Rosário (2012). Segundo o pesquisador, o sintagma escopado na prótase tem uma tendência de assumir o papel de dado, enquanto o sintagma escopado na apódose tende a trazer a informação nova. Nessa visão, leva-se em conta que, no momento da interação entre os falantes, o nível de informatividade é relevante, isto é, há um mínimo de conhecimento partilhado que deve existir para a compreensão mútua, e, a partir desse conhecimento comum, acontece o jogo comunicativo que se estabelece nessa relação dado-novo.

Módolo (2005, p. 174) defende ponto de vista semelhante ao afirmar que a correlação atua de forma argumentativa, pois "concorre para que se destaquem as opiniões 
expressas, a defesa de posições, a busca de apoio, mais do que apenas informar com objetividade os acontecimentos". Consideramos esse fator argumentativo como bastante decisivo nas escolhas de uso da correlação aditiva, bem como um diferenciador no que diz respeito à coordenação aditiva. Podemos notar que, mesmo que o texto analisado seja majoritariamente composto por sequências descritivas ou narrativas, a correlação aparece, na grande maioria dos casos, em sequências argumentativas, como comprovou Gervásio (2016).

Outra questão bastante importante a ser notada na análise do par correlativo não só... mas também é a possibilidade de ocorrerem mudanças naquilo que chamamos de slot da construção, isto é, uma mudança no preenchimento dos elementos que compõem a construção correlata aditiva. Observemos o exemplo (04) a seguir:

(04) Jáas Experiências de Nollet feitas nos vegetaes mostravão bastantemente, que as exhalações, e evaporações delles muito dependem da Electricidade; quem póde duvidar por consequencia que não só os vegetaes, mas os animaes também nasção, cresção, se mantenhão, e se conservem com os influxos della? [...]. (p.117, L.10)

Observando a sequência em (04), em comparação com os exemplos (02) e (03) apresentados, podemos notar a diferença na organização dos itens da construção. Em (02) 
e (03), detectamos que os slots são preenchidos pelos elementos não só (que encabeçam a prótase) [SN ou SV] + mas também (que encabeçam a apódose) [SN ou SV], isto é, não só $[X]$, mas também [Y]. Já em (04), notamos a presença de material interveniente entre o mas e o também na apódose, visto que o sintagma "os animaes" apareceu antes do elemento também, constituindo um exemplo não prototípico desse padrão construcional: não só $[X]$... mas $[Y]$ também. Essa particularidade revela uma atestada mobilidade dos correlatores, que ainda não encontraram forte cristalização na língua portuguesa de então.

Passemos agora ao segundo type com mais sequências encontradas em nosso corpus:

(05) Estes porém, em retribuição, invadirão Narrantsonak, affugentaraõ os missionários Francezes, incendiarão todas as choupana, e pilharão a Igreja, como tambem todos os habitantes daquelle destricto, que se atreviaõ a oppôr-seIhes; a maior parte dos índios fugiraõ, e assim a paz foi de novo restituida aos Colonos. (p.85, L.2)

(06) Vé-se na primeira sala do conselho hum plano do Lazareto, e o retrato de hum homem morto da peste, como tambem os nomes dos directores, e suas semanas de serviço. Dous, ou mais delles se achão presentes todos os dias para receberem as declarações dos Capitães no mesmo instante, em que chegão, para pôr as guardas, e moços de servir, e para dirigir os outros negócios deste vasto estabelecimento. (p.8, L.1) 
Segundo Oiticica (1952, p.52), "é comuníssima a omissão do primeiro termo correlativo". De fato, isso acontece no type X... como também, que é bastante produtivo, com 20,37\% das ocorrências totais, sendo o segundo type em termos de frequência token (22 ocorrências). Os exemplos figurados anteriormente mostram que a primeira parte do par correlato pode ser inferida, tendo em vista a sua não expressão no plano formal.

Em (05), observamos a ocorrência de uma construção prototípica, em que se correlacionam dois sintagmas: "a Igreja" e "todos os habitantes daquelle destricto". De forma semelhante, em (06), o primeiro elemento do par correlato é omitido textualmente, possivelmente antes de "hum plano do Lazareto", mas, diferentemente de (05), são correlacionados dois sintagmas nominais na prótase e dois na apódase, unidos pela conjunção coordenativa aditiva "e".

O type não só... mas é o terceiro mais produtivo entre os padrões construcionais encontrados no século XVIII, tendo sido registrado 18 vezes $(16,6 \%)$ em nosso corpus. Vejamos os exemplos (07) e (08):

(07) Muitos casos se contão de raios, que parecem incríveis, mas os que são verdadeiros se fundão todos no sobredito. [...] He porém preciso advertir, que muitas cousas correm entre o vulgo que não só são exageradas, mas mesmo de todo fingidas. (p.110, L.10) 
(08) Seria desnecessaria a presente Memoria, se as luzes das Sciencias Naturaes estivessem assás espalhadas entre nós, porém como infelizmente assim não he, e a piedade mal entendida continua a fazer o mesmo damno, por isso, desejando concorrer, quanto posso, para o bem publico, me resolvo a publicalla, não só para mostrar evidentemente, que a sepultura nos Templos he nociva, mas para ensinar os meios de remediar os seus máos effeitos, para cujo fim examinaremos [...] (p.3, L.13)

Podemos observar que, tanto em (07) quanto em (08), a apódose traz o argumento principal, mais forte e também mais inesperado. Como é comum na correlação aditiva, o foco da construção está nessa segunda parte da construção. O jogo argumentativo se consolida quando notamos a relevância do enunciado novo acrescido ao já dado, já esperado. Ademais, o uso do mas em (07) e em (08) ratifica essa ideia de que, a partir da semântica de restrição na prótase (o que é comprovado pelo advérbio só) há o estabelecimento, na apódose, do contraste com o já conhecido.

Nesta análise, trabalhamos com a noção de escopo, isto é, pensamos a relação dos elementos constituintes dos diferentes types de pares correlatos com os itens ao seu redor. Segundo Ilari (1992, Apud SOUZA, 2004, p.68), o escopo é definido como o conjunto de conteúdos afetados por algum operador. Nesse caso, consideramos como operadores os pares que encabeçam as construções correlatas aditivas. 
Esses pares, como temos visto, não têm uma configuração fixa, dado que podem variar em seus elementos constituintes: advérbios de negação (não), de restrição (só; somente), de focalização/inclusão (também), conjunções adversativas (mas, porém), elementos comparativos (como), etc.

Sobre o elemento não e sua relevância para a estrutura da correlação, Rosário (2012, p.143) aponta o seguinte: "Sendo formada por um elemento originalmente negativo (advérbio não), a correlação guarda estreita relação com a negação". De fato, é por meio da negação de um elemento, acompanhada da inclusão de outros, que se instaura a correlação aditiva.

Acrescentamos a essa análise as importantes possibilidades que o item não (advérbio de negação) cria quando associado ao elemento só (ou somente), que é veiculador de uma ideia de restrição, na prótase. No exemplo (08), vemos que a associação desses itens no contexto cria um efeito de sentido da negação de um foco (ROSÁRIO, 2012, p.206). Nesse caso, a restrição negativa atua sobre a apódose para ratificar que o objetivo da escrita daquelas Memorias (do livro) não está somente na intenção de provar o perigo das sepulturas nos templos, mas, sobretudo e especialmente, tem o objetivo de ensinar a tratar das consequências dos efeitos que já se notam. 
Além disso, o aparecimento do type não só... mas em sequências não prototípicas também merece nossa atenção. Vejamos os exemplos a seguir, nos quais a ordem dos elementos que encabeçam os pares correlatos está bastante diferente da ordem mais comum e mais frequente. Casos como esses apareceram em apenas duas ocorrências - uma com o par não só... mas e outra com o par não somente... mas - no total de 108 tokens, constituindo aproximadamente 1,85\% das sequências encontradas no século XVIII:

(09) Paraliticos continuando a Electrisar-se, tornarão a ficar Paraliticos, e o que mais he, que alguns sendo só Paraliticos n'hum membro, o ficarão em todo o corpo, mas he tambem mais que certo de ter-se usado nessas curas mal succedidas de comoções, sempre fortes para os doentes; e a Experiência não só mas a razão devem mostrar, que as fortes scyntillas, e comoções, que então usavão, irritando demaziadamente as partes enfermas não podião cauzar bons effeitos; [...]. (p.120-121, L.10)

(10) Deste modo a Electricidade favorece as secreções da natureza, augmenta a circulação dos humores, e deve impedir não somente, mas desfazer as obstruções, e ajudar admiravelmente as evacuações necessárias para o bem da saúde [...]. (p.118-119, L. 10)

Em ambas as ocorrências, a primeira parte do par correlato na prótase, não só em (09) e não somente em (10), aparece após o sintagma por elas escopado, isto é, os dois casos fogem à estrutura mais comum: não só [SN ou SV], mas também [SN ou SV]. Temos, então, casos que se afastam um pouco do núcleo central da categoria. 
Ao considerarmos a noção de prototipicidade, segundo a qual "o protótipo é a entidade central em torno da qual se organiza a categoria, situando-se no centro aqueles exemplares que têm maior semelhança com o protótipo, e na periferia os que têm menor semelhança" (NEVES, 2006, p.22), os chamados exemplos periféricos não constituem um empecilho à caracterização da categoria, mas são apenas exemplos radiais que partilham algumas características com os elementos centrais, diferindo-se em alguns pontos. Vejamos o que diz a esse respeito Gonçalves (2001, p. 188):

Assim como para a categorização de objetos naturais e culturais, dentro do princípio de categorização linguística, é possível distinguir termos de nível básico, e portanto, membros mais prototípicos (ou mais centrais) de uma categoria, de termos de nível não básico, representantes de membros marginais da mesma categoria. Um dos critérios que distingue os termos de nível básico é a sua alta frequência de uso, embora não seja este um critério determinante. [...].

No caso dos exemplos (09) e (10) apresentados, consideramos que eles constituem apenas exemplares não prototípicos, mas ainda dentro do grupo das construções correlatas aditivas, que são nosso foco de análise.

Analisemos, agora, nosso quarto type mais frequente: não somente... mas também, que apareceu em mais de $14 \%$ das ocorrências totais. 
(11) Nós presumimos bem, que a nação dispenderia considerável soma de dinheiro na construcção de hum Lazareto; mas pensamos também, que as vantagens commerciaes, que ella tiraria daqui, compensarião assás seu desembolço: não somente os navios que carregão em Turquia, mas tambem os que vem de todas as portos do Mediterraneo, contribuirião para pagar as despezas. (p.77-78, L.1)

No trecho destacado no exemplo (11), defende-se a construção de um lazareto, reconhecendo-se os altos custos, mas argumentando que haveria algumas vantagens comerciais decorrentes dessa edificação. Essas vantagens que compensariam as despesas são apresentadas por meio do par correlato não somente... mas também, sendo "os navios que carregão em Turquia" desfocalizados pela presença de não somente. Por sua vez, o termo "os que vem de todas as portos do Mediterraneo", a informação nova, principal, o argumento mais forte, é encabeçado pelo elemento de contra expectativa mas e pelo inclusivo também.

Quanto ao focalizador também, observamos que é um elemento que merece destaque no estudo das construções correlatas aditivas, visto que aparece não somente nesse par em questão, mas em outros três, figurando em quatro dos onze types de pares correlativos encontrados no século XVIII (não só... mas também; X... como também; não somente... mas também e não só... como também). Esse elemento colabora para a construção do sentido na sequência correlativa, tendo o 
papel de auxiliar na inclusão da informação nova que se assenta na apódose. Vejamos o que diz Possenti (1992, Apud SOUZA, 2004, p. 68) sobre esse advérbio:

advérbios como também pressupõem sempre algo (seja uma coisa, uma ação, um evento, uma qualidade, uma relação, etc.) ao qual se soma, explicitamente, outra coisa, evento, qualidade, etc., que é o escopo de também. O usual é que apareçam explicitamente tanto o elemento pressuposto quanto o que se inclui [...].

Apesar de admitirmos a importância do item também para diversos pares correlatos, entendemos que não se trata de um elemento indispensável e essencial, já que a ideia de inclusão já está presente no mas (assim como também no como, em outros types). De fato, em sete types, conforme atestado na tabela 1, o também não aparece, como ocorre em (13) a seguir, que difere de (12) pelo não acréscimo de também ao não somente... mas:

(12) Vimos também alli os meios seguros, até aqui sabidos, pelos quaes se podem moderar, ou corrigir os seus terríveis effeitos: examinemos agora, se por meio da sepultura dos cadáveres se evitão não sómente a producção destes venenos, mas tambem os seus effeitos, para o que examinaremos a podridão dos cadaveres debaixo da terra. (p.16-17, L.13)

(13) A cal viva, pela affinidade, ou attracção, que tem com os humores animaes, desorganisa, e destroe em muito pouco tempo as partes molles, e por esta razão não sómente serve, para se combinar com o gaz ácido carbonico (§. XXIV ); mas 
para apressar a resolução dos cadáveres, o que não faria, se fosse misturada com o vinagre; [...] (p.33, L.13)

Analisamos, a partir de agora, os quatro últimos types atestados em nosso corpus, constituindo a menor frequência de ocorrência. São eles: não somente... porém, não só... mas até; não só... senão ainda e não somente...como.

O padrão não somente... porém apareceu em apenas duas ocorrências, indicando um percentual de 1,85\% dos casos. Vejamos o exemplo (14) a seguir:

(14) Tão somente podemos certificar, que inserindo nas manufacturas, e commercio esta quinta materia (Canamo preparado) que se poderia suppor creação nova, he não sómente ajuntar huma quinta ás quatro, que ha tanto tempo se conhecem; porém, para me servir de termos Mathematicos, he ainda elevar cada huma dellas muito acima da quinta potência. (p.71, L.7)

Em (14), o par correlato está cercado de orações de diferentes níveis. Há a oração relativa "que ha tanto tempo se conhecem", encaixada à prótase, além de uma oração hipotática adverbial final reduzida de infinitivo, "para me servir de termos Mathematicos", encaixada à apódose, que se inicia com a conjunção porém. Um elemento importante nesse arranjo é o advérbio “ainda” (logo após a apódose). Certamente a inclusão desse elemento no discurso contribui para o incremento do valor de adição veiculado pela segunda parte do par corretivo.

Para Heine e Kuteva (2006, p. 60), um item pode ter novos significados evocados por novos contextos de uso. É o que 
os autores chamam de dessemantização ou apagamento semântico (semantic bleaching):

Este parâmetro de gramaticalização diz respeito ao surgimento de novos significados gramaticais, em que uma estrutura já existente quando usada em novos contextos é dessemanticizada, isto é, perde partes do seu significado e é reinterpretada nesses contextos expressando um novo significado gramatical.

No caso das construções correlatas aditivas, entendemos que o elemento porém passou por esse processo, perdendo parte de seu significado mais comum - de oposição - e ganhando uma semântica nova - de adição. Esse processo certamente é favorecido pelo próprio contexto. Afinal, no dado (14), há a inclusão do advérbio "ainda", que contribui com a semântica de adição.

Na construção aditiva, diante desses fatores contextuais, o elemento porém é reinterpretado, adquirindo um novo sentido. A inserção desse elemento, encabeçando diversos casos de apódose, encaixa-se na máxima explicativa de Heine e Kuteva (2007, p.39) sobre o processo em questão: "O uso de uma expressão linguística $E$ em um novo contexto $C$ implica que $E$ perde parte do seu significado que é incompatível com C [...]". Sendo assim, essa extensão e consequente reinterpretação do sentido estão ligadas ao contexto linguístico novo em que o conector é usado. 
É curioso que o porém já não seja utilizado em dados sincrônicos da correlação aditiva (ROSÁRIO, 2012). Mesmo no século XVIII, a sua frequência de uso já era bastante escassa. Entretanto, a sua incidência no slot do correlator da apódose segue a mesma lógica do mas, tendo em vista padrões do tipo não somente... mas. Afinal, ambos os conectivos (mas e porém) são prototipicamente ligados à noção de oposição. Essa constatação revela uma importante propriedade da composição morfossintática da correlação aditiva, que é a presença de elemento contrastivo no segundo correlator da apódose.

Vejamos o único caso de não só... mas até encontrado em nossos dados:

(15) Daqui vem que no nosso ár commumente nos tempos frios e serenos, e assim tambem nos nevoeiros, que trazem comsigo máo cheiro, se acha sempre maior abundância de Electrico fluido; a elle atribuem hoje não só as fulgurações nocturnas, e vespertinas, as auroras boreaes, os fogos fatuos, as nuvens brancas de noute, as Trombas marinas, os furacões, os Terramotos, mas até os mesmos ventos, e se os Tuffoens e como costuma acontecer em tudo, veio o tempo, e a moda que a Electricidade fosse para os Fysicos hum armazem commum para explicar por ella tudo o que sucede na natureza.[....] (p.101-102, L.10)

O dado (15) é um exemplo de uma construção correlata aditiva suboracional. Na prótase, são elencados diversos sintagmas nominais por meio de vírgulas e, na apódose, figura o elemento menos esperado, introduzido pelo mas 
até: "os ventos". Se compararmos os pares não só... mas até e não só... mas ainda, podemos notar que há uma grande semelhança no que diz respeito ao efeito de sentido provocado pelo uso dos elementos até e ainda. Afinal, ambos guardam uma semântica original de tempo.

Vejamos mais um par correlativo aditivo:

(16) ahi cada escravo toma á sua conta numa fileira de algodoeiros, que a não deve deixar até o fim, colhendo não só, o que se achar por cima,_senão ainda pelo chão, no que deve o feitor pôr hum extremo cuidado, para cujo effeito os deve ter sempre debaixo da vista [...]. (p.59, L.8)

No único caso de não só... senão ainda encontrado do type em questão, podemos notar que não se trata de uma sequência que muito se difere dos demais padrões. No exemplo (16), temos a correlação da cláusula "o que se achar por cima", escopada por não só, na prótase, com o "(o que se achar) pelo chão", escopada por senão ainda, na apódose.

Quando comparamos esse type aos demais, notamos que a presença do elemento senão em um único padrão pode ser explicada pelo fenômeno da analogia, no qual um elemento com carga semântica próxima àqueles mais típicos (como o mas), quando inserido em um contexto favorável à aproximação desse sentido, ocupa seu espaço funcional. É o que ocorreu também com porém, indicado anteriormente, no dado (14).

No que diz respeito ao par não somente... como, igualmente ocorreu a dessemantização do segundo elemento correlator, 
na apódose. De fato, como, porém e senão passaram por um processo de mudança, sendo recrutados para o esquema correlativo aditivo. Vejamos como isso pode ser percebido no exemplo (17) a seguir:

(17) Esta questaõ hé na verdade assas interessante, naõ sómente porque se tracta de indagar, se hum objecto da Agricultura, hoje da primeira necessidade, hé nocivo á saude humana, em cuja conservaçaõ devemos pór o nosso primeiro cuidado, como porque, sendo muitas, e diversas as doenças epidemicas, e, por conseguinte, devendo ser igualmente muitas, e diversas as causas, que a produzem, e sendo infelismente desconhecidas quasi todas as causas epidemicas, hé bem manifesto, que na resoluçaõ da presente questaõ se dará hum grande passo em Medicina; porque se se verificar, que o arros hé de facto causa de epidemia [...]. (p.1, L.12)

Na sequência supraoracional ilustrada em (17), temos a presença de diversas orações encaixadas dentro do escopo de não somente e como, com atenção especial às causais, iniciadas pela conjunção "porque", tanto na prótase quanto na apódose. Podemos perceber que, na segunda parte da construção correlata aditiva (apódose), o conector como não veicula o sentido comparativo, mas acrescenta a informação menos esperada e mais importante sobre as epidemias que se julgam estar relacionadas ao cultivo de arroz. Para o enunciador, é interessante refletir sobre a cultura do arroz e suas possíveis consequências nocivas não apenas porque esse é um dos itens centrais na alimentação, mas principalmente porque se daria um grande passo na Medicina, descobrindo que o arroz é causa de epidemias. 
Assim, encerramos esta breve análise de alguns padrões correlativos aditivos atestados no século XVIII. Na seção seguinte, apresentamos algumas generalizações, com base nas análises realizadas.

\section{CONSIDERAÇÕES FINAIS}

As construções correlatas aditivas atestadas nos textos do século XVIII revelaram traços muito peculiares em seu modo de configuração, tanto no nível formal quanto semântico, e, nesse sentido, têm se mostrado bastante distintas daquilo que tradicionalmente se denomina coordenação.

Nesse sentido, nosso estudo se alinha às conclusões de Rosário (2009, 2012, 2013, 2015, 2017), que se dedicou ao estudo da mesma temática no século XXI, e de Gervasio (2016), cuja análise teve como foco os séculos XIX e XX. A correlação aditiva, de fato, presta-se a contornos de maior argumentatividade. Ademais, no plano morfossintático, organiza-se em prótase e apódose, com correlatores descontínuos. Tudo isso embasa a defesa de que não são estruturas de coordenação, como preceituam vários gramáticos normativos. A diferença em termos formais é bastante flagrante.

Nossa análise demonstrou a diversidade de instanciações da correlação aditiva, revelando sequências que se estabeleceram no nível supraoracional, outras no nível oracional e, surpreendentemente, na maioria dos casos, em sequências 
suboracionais. Essa, de fato, é uma propriedade comum à coordenação aditiva, mas na correlação, essa propriedade ganha contornos diferenciados, tendo em vista a hierarquização típica das informações, no jogo entre prótase e apódose.

$\mathrm{Na}$ correlação aditiva, atestamos um verdadeiro quadro de variação construcional (ROSÁRIO, 2012, p.199), tendo em vista o uso de elementos inesperados como porém, mas ainda, senão ainda, entre outros, visto que não estão registrados nas gramáticas normativas contemporâneas. Essa constatação revela a grande maleabilidade da correlação aditiva, que se configura de maneiras distintas, abrigando elementos originários de outras categorias gramaticais em seu bojo, especialmente advérbios. Nesse sentido, a correlação aditiva é versátil e muito suscetível a pressões discursivas, haja vista sua própria configuração morfossintática.

Apesar de reconhecermos que há muito que ser desenvolvido no estudo da correlação, é possível afirmar que as pesquisas sobre esse tema vêm se ampliando no quadro dos estudos linguísticos contemporâneos, especialmente sob a égide dos pressupostos da Linguística Funcional Centrada no Uso (LFCU). Esperamos, portanto, que os dados analisados neste trabalho possam contribuir para a agenda de pesquisas sobre as construções correlatas aditivas em língua portuguesa. 


\section{REFERÊNCIAS}

BECHARA, Evanildo (2003). Gramática Escolar da Língua Portuguesa. Rio de Janeiro: Lucerna.

(2009). Moderna Gramática Portuguesa. Rio de Janeiro: Nova Fronteira.

BYBEE, Joan (2003). "Mechanisms of change in grammaticization: the role of frequency". In: JOSEPH, Brian; D.; JANDA; Richard D. The handbook of historical linguistics. Malden: Blackwell Publishing, p.624-647.

(2007). Frequency of Use and the Organization of Language. Oxford: University Press.

CASTILHO, Ataliba Teixeira (2010). Nova Gramática do Português Brasileiro. São Paulo: Contexto.

CUNHA, Celso; CINTRA, Lindley (2001). Nova Gramática do português contemporâneo. Rio de Janeiro: Nova Fronteira.

CUNHA, Maria Angélica Furtado; BISPO, Edvaldo Balduíno; SILVA, José Romerito. (2013). "Linguística Funcional Centrada no Uso: conceitos básicos e categorias analíticas". In: CEZARIO, Maria Maura; CUNHA, Maria Angélica Furtado (Orgs.). Linguística centrada no uso: uma homenagem a Mário Martelotta. Rio de Janeiro: Mauad - Faperj, p.13-39.

; COSTA, Marcos Antônio; CEZÁRIO, Maria Maura. (2015).

"Pressupostos teóricos fundamentais". In: CUNHA, Maria Angélica; OLIVEIRA, Mariangela Rios; MARTELOTTA, Mário Eduardo (Orgs.) Linguística Funcional: teoria e prática, 1.ed. São Paulo: Parábola Editorial, p.21-47.

GERVASIO, Tharlles Lopes (2016). A construção correlata aditiva nos séculos XIX e XX: uma proposta de análise centrada no uso. (Dissertação de Mestrado) - Universidade Federal Fluminense, Instituto de Letras, Niterói - RJ.

GOLDBERG, Adele E. (1995). Constructions: A Construction Grammar Approach to Argument Structure. Chicago: The University of Chicago Press. 
GONÇALVES, Sebastião Carlos Leite (2001). "Orações Subjetivas e Teoria dos Protótipos". SCRIPTA, Belo Horizonte, 5(9), 183-196.

HEINE, Bernd; KUTEVA, Tania (2006). The Changing Languages of Europe. Oxford: University Press.

(2007). The Genesis of Grammar: A Reconstruction. Oxford: University Press.

HENRIQUES, Cláudio Cezar (2003). Sintaxe Portuguesa para a linguagem culta contemporânea. Rio de Janeiro: Oficina do Autor.

KURY, Adriano da Gama (2003). Novas Lições de Análise Sintática. São Paulo: Ática.

LUFT, Celso Pedro (2000). Moderna Gramática Brasileira. São Paulo: Globo.

MATEUS, Maria Helena Mira et al (Org.) (2003). Gramática da Língua Portuguesa. Lisboa: Caminho.

MELO, Gladstone Chaves (2001). Gramática Fundamental da Língua Portuguesa. Rio de Janeiro: Ao Livro Técnico.

MÓDOLO, Marcelo (2005). “A estrutura correlativa aditiva 'não só... mas também' de uma perspectiva multissistêmica". Estudos Linguísticos. São Paulo, Campinas. p.171-176.

NEVES, Maria Helena de Moura (2006). Texto e gramática. São Paulo: Contexto.

OITICICA, José (1952). Teoria da Correlação. Rio de Janeiro: Organizações Simões.

RAPOSO, Eduardo Buzlago Paiva et al (Org.) (2013). Gramática do Português. Lisboa: Calouste Gulbenkian.

RIBEIRO, Manoel Pinto (2004). Nova Gramática Aplicada da Língua Portuguesa. Rio de Janeiro: Metáfora.

ROCHA LIMA, Carlos Henrique (1999). Gramática Normativa da Língua Portuguesa. Rio de Janeiro: José Olympio.

ROSÁRIO, Ivo da Costa (2009). "Construções aditivas - uma análise funcional". In: OLIVEIRA, Mariangela Rios de; (Orgs.). Pesquisa 
em linguística funcional: convergências e divergências. Niterói - RJ: Leo Christiano Editorial, p.52-62.

(2012). Construções correlatas aditivas em perspectiva funcional. Tese (Doutorado em Letras), Universidade Federal Fluminense, Instituto de Letras, Niterói - RJ.

(2013). "Construções correlatas aditivas na perspectiva da Linguística Funcional Centrada no Uso". In: Anais do IV Seminário Internacional do Grupo de Estudos Discurso \& Gramática e XVII Seminário Nacional do Grupo de Estudos Discurso \& Gramática: Teoria da gramaticalização e Gramática de construções. Natal - RN: Editora da UFRN, p.26-41. In https://degnatal.files.wordpress.com/2015/04/teoriada-gramaticalizac3a7c3a3o-e-gramc3a1tica-de-construc3a7c3b5es.pdf. Acesso em 06.Dez.2017

(2015). "Sintaxe Funcional". In: OTHERO, Gabriel de Ávila; KENEDY, Eduardo. (Orgs.). Sintaxe, sintaxes: uma introdução. 1.ed. São Paulo: Contexto, p.143-162.

; OLIVEIRA, Mariangela Rios (2016) "Funcionalismo e abordagem construcional da gramática". Alfa: Revista de Linguística (UNESP. Online), 60, 233-259. In http://www.scielo.br/pdf/alfa/v60n2/1981-5794-alfa-60 -2-0233.pdf. Acesso em 06.Dez.2017

(2017) "Construções correlatas aditivas e disjuntivas". Revista Odisseia, v.especial, p.103-124. In https://periodicos.ufrn.br/odisseia/ article/view/12903. Acesso em 06.Dez.2017

SOUZA, Edson Rosa Francisco. (2004). Os Advérbios focalizadores no Português Falado do Brasil: uma abordagem funcionalista. Dissertação (Mestrado em Estudos Linguísticos - Área de concentração: Análise Linguística). UNESP, São José do Rio Preto.

TRAUGOTT, Elizabeth Closs; DASHER, Richard. B. (2002). Regularity in semantic change. Cambridge: University Press.

; TROUSDALE, Graeme (2013). Constructionalization and constructional changes. Oxford: Oxford University Press. 
Ivo da Costa do Rosário é Doutor e Mestre em Letras Vernáculas - Língua Portuguesa (UFRJ) e mestre e doutor em Letras - Estudos Linguísticos (UFF). É docente de Língua Portuguesa do Instituto de Letras da UFF e credenciado no Programa de Pós-graduação em Estudos de Linguagem da UFF. Atua na graduação, no mestrado e no doutorado em atividades de docência, pesquisa e orientação acadêmica, nas áreas de sintaxe, linguística funcional e conexão de orações. É autor de vários artigos e capítulos de livro. Participa do grupo de pesquisa D \& G (Discurso \& Gramática) e é líder do CCO (Conectivos e Conexão de Orações). E-mail: rosario.ivo3@gmail.com

Brenda da Silva Souza é Mestranda em Estudos de Linguagem pelo Instituto de Letras da Universidade Federal Fluminense (UFF). É graduada em Letras - Português/Literaturas pela mesma Universidade. Já atuou como bolsista de Iniciação Científica (PIBIC-UFF) durante os anos de 2016 e 2017, estudando o tema da correlação aditiva. Atualmente é integrante dos grupos de pesquisa Conectivos e Conexão de Orações (CCO) e Discurso e Gramática (D \& G), ambos com sede na UFF. E-mail: brendasouza045@ gmail.com. 